\title{
Deconstruction Analysis: The Ideas of Keeping Tradition in "No Witchcraft for Sale" by Doris Lessing
}

\author{
Putri Ayu Rezkiyana \\ Postgraduate Program in English Language Studies \\ Sanata Dharma University \\ Yogyakarta, Indonesia \\ putri.ayurezki@gmail.com
}

\begin{abstract}
A short story of Doris Lessing's "No Witchcraft for Sale"tells about a native African named Gideon working for a missionary family the Farquars. This shows how the relationship between the master and the servant go on and also how the natives are treated. The story is related to the postcolonial reading which not only gives the proofs of oppression towards the natives as usual, but it also tries to find new meanings. By using Critical Discourse Analysis (CDA) method with deconstruction theory by Derrida, this writing aims to dismantle the hidden meaning portrayed in the idea of keeping tradition that becomes the center of the text. The writer also includes transitivity analysis taken fromHalliday'sSystemic Functional Grammar (SFG) (2004) to findthe linguistic evidences in which they are used to produce the binary oppositions that exist in the text. These polarities actually contains meanings which already set up or fixed at the first reading where, in this story, native is usually described as the oppressed since he insists on preserving cultural heritage, and the Masters are the oppressor since they want to take the traditional culture. In deconstruction, the meaning polarities are inverted so that it regenerates new ideas over the text called as dissemination. Keeping tradition which is considered to bring goodness is no longer seen as it is, but tradition is construed as being egocentric and support particularism. It is close minded and difficult to receive updates or renewals.
\end{abstract}

Keywords: transitivity analysis, deconstruction, post-colonialism

\section{INTRODUCTION}

Postcolonial era is commonly defined as the moment after colonization where the colonized nation had been freed from the colonizer. Frantz Fanon through The Wretched of the Earth (1961)argues that 'the first step for 'colonized' people in finding a voice and an identity is to reclaim their own past, and the second one is 'to begin to erode the colonialist ideology by which that had been devalued' (Barry, 2002: 193). Thus, it can be seen that there is a struggle from the colonized people to detach themselves from colonial power. However, it is not that simple. The colonial traces still remain in the social-cultural aspects that embodied in term of, for example, architecture, education system, governmental system, and even the way of thinking. Therefore, 'it has been suggested that it is more helpful to think of postcolonialism not just as coming literally after colonialism and signifying its demise, but more flexibly as the contestation of colonial domination and the legacies of colonialism' (Loomba, 2000:13).

Such ideas also happens in No Witchraft for Sale (1951), a short story written by a British author Doris Lessing. The story tells how Gideon, a black native African, lives with his master, The Farquars, who are white European people. 'White' refers to the group of people categorized as Western. The story portrays the relation between White people and the native living together in farm area. The setting is inNigeria, West Africa, in 1960s. There was a cultural clash at that time between the natives who owned Black culture and the foreigners who were the White European culture. Here, the story reflects on how the Farquars, a missionary family, treat their servant named Gideon (including his family) who is a black-native Africa. Gideon as the representative of ex-colonized people insisted on keeping his cultural heritage by not telling the secret of herb medicine to white people who are the Farquars and the scientists.

This writing aims to criticize the idea of keeping tradition done by the native in its relevance to postcolonial reading. It guides into a question in what extend the tradition should be preserved in postcolonial era. This is because the situation has changed in postcolonial period in whichex-colonialized peopleand theex-colonizers can have a good relationship, and even live live hand in hand. Being sceptic with such notion, the writer tries to find different point of view of postcolonial reading by using deconstruction analysis. 'Deconstruction works to undo the idea - according to Derrida, the ruling illusion of Western metaphysics - that reason can somehow dispense with language and achieve a knowledge ideally unaffected by such mere linguistic foibles' (Norris, 2002: 19). Western metaphysics refers to the idea that Western ideas that has been patternized in the text or context which shows the superiority of Western civilization. In deconstruction, this idea is inverted so that it overcomes new possible meanings. This is what so called by Derrida as Undécidable which, then, is to dismantle the metaphysic hierarchy that exist in the text.

There are four main steps to achieve the goal of deconstruction. The first one is by finding the center of the text. This part is found in the climax of the story where the accumulation of the problem occurs. The next is by finding the binary logics. 
The binary opposition shows meaning polarity that exists in the story, for example day and night, male and female, black and white, colonized and colonizer, and so on. To support the analysis, the writer applies linguistic analysis by using Systemic Functional Grammar (SFG) developed by Halliday (2004) in order to discover the meaning polarities. Linguistic evidence is important since language can reflect the ideology of the writer or the meaning inside the text. Pierre Bourdieu argues that language can be viewed as the instrument of a power (Bourdieu, 1982: 60). what comes up in the language use is representing the author's idea about certain thing purposed as a discourse. Basically, there are three metafunction suggested in SFG which are ideational, relational, and textual. The writer only focuses on the ideational metafunctionby using transitivity analysis to see the dominant process in the story. Transitivity analysis is about doing and happening which can be seen from the material process, and also about cognitive process, being and behaving which appear in verbal, mental, behavioral, and existential processes ( Lock, 1996: 67-143). By owning linguistic evidences from the text, it proves that linguistic analysis has salient role to be put in the literary criticism.

By using the concept of différance, these binary oppositions are inverted so that the meaning is no longer similar to the previous one. For example, the binary logic between native and visitor is commonly understood that native is the origin people because they are who dwell there at the first time. However,by having been invert, it can be interpreted that visitor is also the native since they also live first before the descendants of the natives. As the fourth step, there is meaning dissemination in which the new possibilites are found. At the end of this paper, the writer also discusses the meaning dissemination brought into context in the real world.

\section{FINDINGS AND ANALYSIS}

Center of the Text

This part is to explain the synopsis as the abstract of the story. It involves the analysis on the elements of narrative developed by Labov (1981). The elements consist of six parts which are abstract, orientation, complication, evaluation, resolution and the coda. In this session, the abstract is depicted in a bundle of narrative begun with the exposition until the conclusion (coda). Exposition is usually used to introduce the characters and the setting of time and place so that the readers know the context.

The exposition begins from paragraph 1 to paragraph 3 that portrays the characters introduces the characters including the relationship among them. This is the place where the missionary family lived with their servant named Gideon who is a Black native. At the beginning, it tells good relationship between the master and their servant, portrayed by the way Gideon keeps Teddy, the son of the Farquars. This exposition is not the essential one, but it influences the analysis on what kind of intension appears between them.

The story is progressed by the incident of Teddy who got spatted by a snake, and Gideon can cure him using herb recipe, a part of traditional medicine. The medicine becomes the central of attraction to run the story. Meanwhile,complication happened because one problem has just been solved but other problem occurs. The complication is when the scientists knew about the news of herb medicine and they came to look for it. When Gideon decided not to tell the medicine to the Whites, and this part evokesthe conflict. For the climax, it is when Gideon finally invited the scientists and the Farquars walked along the bush and picked up the random plant. The narrator directs the readers that finally the native wanted to show the plant they were reffering to, but actually not. By picking up the random plant actually wants to tell that Gideon got furious and did not care about their intensions. He did not take for granted about that plant because he kept not telling the truth.

After giving them a false plant, Gideon went home without any notice to others. It is called as the turning point of the story or resolution. The consequences of this part is the scientists got a wrong plant for medicine, the scientists and the Whites never knew about the truth, and the natural sources as the traditional medicine was saved from comodification. At the end of the story, it is told that Gideon had a good relationship again with the Farquars. The moment happened in the past seems not influence their relationship although it once had been distracted because of a request to know herb medicine.

As the evaluation, the story actually can be end up easily. The problem is not getting complicated if Gideon told the secret. It can be seen that there are two interests that have not been met which are between the Whites and Gideon as the native. Perhaps, this is because both parties do not really know each other characteristics. The Whites can be understood that they are too sudden and too direct in telling Gideon about their purpose. Meanwhile, the native who accustomed to deal with tradition sees negatively the idea of telling the medicine to the strangers. It seems that Dorris Lessing wants to suggest the absence of understanding a culture which is considered as new discourse.

The center of a text functions as the umbrella for the analysis which shown in the climax. It occurs on which Gideon did not want to tell the medicine and gave random plant to the scientist. It lies firstly in the inciting moment of the story as reflected in paragraph 17 and 18, which is more emphasized in paragraph 18.

Gideon looked from Mrs. Farquar to Mr. Farquar, and then at the little boy, who was showing great importance because of the occasion. At last he said grudgingly: "The Big Baas want to know what medicine I used? " He spoke incredulously, as if he could not believe his old friends could so betray him. ...Gideon listened, his eyes bent on the ground, the skin of his forehead puckering in 
discomfort. When Mr. Farquar had finished he did not reply... (Par.18)

In postcolonial reading, the colonial tradition is still exist although the colonialism has been vanished. It is where the borrowed culture from colonials compets to the local culture from the natives. This condition is reflected in Gideon's character in which he got conflict on whether or not giving the information about the plant (paragraph 17-18). Regarding this, take a look back at the exposition, we see how the Farquars treat Gideon as well as Gideon feel of being together with them as his masters. However, after the bad moment happened to the Teddy, who is the only son of the Farquars, it more describes Gideon's behaviour towards the Whites (par 18). He tried hard to keep his cultural heritage in order not to be destructed by non-native people. Henceforth, the analysis works to examine the real motives of Gideon by seeing his attitudes.

\section{Transitivity Analysis}

There are six processes in transitivity analysis, which are material, relational, verbal, mental, existential, and behavioural. It can be seen in the table 1 .

Table. 1. The percentage of transitivity analysis in Doris Lessing's "No Witchcraft for Sale".

\begin{tabular}{|c|c|c|c|}
\hline NO & PROCESSES & FREQUENCY & PERCENTAGE \\
\hline 1 & Material & 106 & 44,16 \\
\hline 2 & Relational & 50 & 20,83 \\
\hline 3 & Verbal & 33 & 13,75 \\
\hline 4 & Mental & 30 & 12,5 \\
\hline 5 & Existential & 15 & 6,25 \\
\hline 6 & Behavioural & 6 & 2,5 \\
\hline & TOTAL & 240 & 100 \\
\hline
\end{tabular}

The result of this transitivity analysis shows the material process is $44,16 \%$, the relational process is $20,83 \%$, while other processes are less than $15 \%$. The material and relational processes have the high percentage than others because it contains the action process about the relation between Whites, who are represented by The Farquars and the scientist, and the natives. The writer, later on, talks about the idea of postcolonial through this analysis as explained below in detail in each process.

\section{Material process}

Material process is about action and goal. There are actor and receiver in which the 'give' and 'receive'process are reflected in the sentence. In this short story, there are 108 material processes contains in the sentences or clauses. The most frequent material process belongs to Gideon's actions functioned as actor and agent, which is 33 out of 108, or 28,3\%. See the examples of material process found in the story.

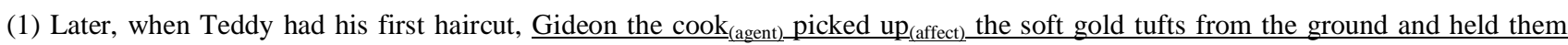
reverently in his hand.(par.2)

(2) $\underline{H e}_{\text {(agent) } \text { finally lifted }}$ (process) $T e d d y_{\text {(affected) }}$ gently into his mother's arms, and said: "His eyes will get better." (Par.10)

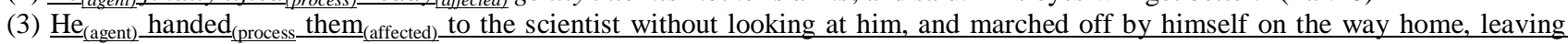
them to follow him if they chose. (Par. 26)

(4) And he $_{(\text {agent) }}$ raced $_{\text {(process) }}$ in circles around the back child until he was frightened, and fled back to the bush. (Par.5)

(5) $\underline{\mathrm{He}}_{(\text {agent) }}$ could not bring $_{\text {(process) }}$ himself $_{\text {(affected) }}$ to say he was sorry; but he could not bear to lose Gideon's affection either. (Par.7)

(6) Also, he (actor) $_{\text {offered }}$ (process) Gideon a present $_{\text {(affected) }}$. (Par.18)

(7) ...how a useful medicine could be made out of the root, and how it could be put on sale, and how thousands of people, black and white, up and down te continent of Africa, could be saved by the medicine when that spitting snake filled their eyes with poison. (Par 18)

In examples (1) to (3), the agent is Gideon who did the actions, while in the rest examples from (4) to (8), the actor or agent is done by other characters. For example, in (4), (5), and (6), the doer is from the Farquars. The most frequent Gideon occurs in the story as the doer that contained in the material process, it means that the role of Gideon is significant. Meanwhile, the following occurrence that also places the second number after Gideon's frequency is the Farquars or the white people. It can be inferred that those two have polarity in meaning which, among of them, are master and servant, native and foreigner, and black and white. However, this argument about binary opposition is strengthened with other results of process.

\section{Relational Process}

The relational process is the second highest percentage in the text. The most frequent relational process tells about Gideon's property and the relation between Gideon and the Whites, while the others are about Teddy's propeties, medicine, 
native, and Whites. Relational process is identified by the use of linking verbs. Here are the sentences that contains relational processes.

(8) ... he was one of the few natives, who had his wife and children in the compound and never wanted to go home to his kraal, which was some hundred of miles away. (Par.3)

(9) His face was sullen and hostile...(Par.19)

(10) Mrs. Farquar was fond of the old cook because of his love for her child. (Par.2)

(11) Little Yellow Head is the most good thing we have in our house. (Par.3)

(12) The Farquars were very religious people... (Par.4)

(13) Their feeling about the miracle (that was how they thought of it) were so strong and deep and religious, that it was distasteful to them to think of money. (Par.16)

(14) They were all quite silent: the Farquars because they were angry, the scientist because he was being proved right again. (Par.24)

In (8), for example, Gideon's position among other natives is different because he was working and living with his White master. In (32), the relational process tells the identity of the subject (TheFarquars).

\section{Verbal Process}

Verbal process is identified by the action such as saying, telling, explaining, calling, etc., which is used mouth to deliver the speech/the utterance. In this short story, the frequency of using verbal process is 36 or $14,7 \%$ in which the speaker is dominated by Gideon, Teddy, and Mrs. Farquar. The example of verbal processes in the short story can be seen as follows.

(15) But they went on persuading and arguing, will all the force of their exasperation; and Gideon continued to say that he could not remember... (Par.21)

(16) He said all these things one after another, and seemed not to care they were contradictory. (Par.21)

(17) The scientist, who also this time had been leaning back in a big chair, sipping his coffee and smiling with skeptical good humor, chipped in and explained all over again, in different words, about the making of drugs and the progress of science. (Par.18)

(18) Mr. Farquar began explaining how a useful medicine could be made out of the root,....(Par.18)

(19) The scientist..... explained all over again, in different words, about the making of drus and the progress of science. (Par.18)

The verbal processes utered by Gideon show that he is persisting to keep his heritage. He even performed unwilling attitudes towards his master because of his disappointing of being betrayed. In the story, it is said the relation between Gideon and the Farquars is just like a best friend, but the Farquars seemed do not understand Gideon as the native. We can also find the discussion done by the Farquars and the scientist when they are talking about the plants to be used as medicine. There is different perspective between the scientist and the Farquars in which the scientist focuses the drugs to get money while the Farquars focuses on the humanity value. However, one thing they are targeted is the secret plant to be commodified so that they tried hard to ensure Gideon by long explanation about how useful the medicine, that can be seen in (18) and (19).

4. Mental

Process

Mental process is signified by perceiption, afffection, and cognition. In this short story, we find that mental processes can show what characters think or perceipt from the others. Mental processes belongs to Mrs. Farquar that show the attitudes towards Gideon or natives are seen in the example (20) to (22).

(20) ....and they were touched by the pleasure of their servants,.. (Par.1)

(21) ... a white man uses toward a servant, expecting to be obeyed. (Par.7)

(22) She had scarcely heard Gideon's words; but when she saw that her remedies had no effect at all, and remembered how she had seen natives with no sight in their eyes, because of the spitting of a snake, she began to look for the return her cook. (Par.9)

(23) ..., but they would never know it. (Par.20)

(24) The Farquars could hardly recognize their gentle, lovable old servant in this ignorant, .... (Par.21)

(25) We do not know. We have never heard of the root. (Par.29)

In (20) and (21) describes the relation between the master (Mrs. Farquar) and Gideon. The mental process in those sentences tells that the nature of Whites or the master feels proud when they are served and obeyed, and the position of the person who follow them is below them who is the servant. Meanwhile, in (24) there is distrust from Mrs. Farquar to Gideon in curing the Teddy's eyes. Mental processes that describe the Farquars:

\section{Existential Process}

In existential process, it is usually signified by the word 'there' to show the existent towards something. Here are the sentences that show the existential process: 
(26) ... but there was a grave formality in his voice that made Teddy pout and sulk away. (Par.7)

(27) ... that there is an ancient wisdom of leaf and soil and season... (Par.11)

(28) This was the kind tale they told. (Par.13)

(29) There was silence after this further explanation. (Par.19)

In the example (26), it shows the existence of circumstance where Teddy felt discomfort to show his apologize to Gideon. (27) and (28) are the secret medicine which is a part of natural heritage, while in (29) is about the reaction of Gideon when he was asked about the herb medicine.

\section{Behavioural Process}

Behavioral process is the process that contains unconscious mind such as shout, smile, and laugh. In this short story, the process can be seen in the following sentences:

(30) Then he smiled at the little boy... (Par.2)

(31) And Gideon would laugh and say: "Very clever, Little Yellow Head." (Par.5)

From the behavioral process in (30) and (31), those show how Gideon behaved towards Teddy. It seems Gideon was happy and proud of Teddy. These actually identify that Gideon has good behaviour to his son's master. The analysis of ideational metafunction in the story reflects meaning polarity that can be shown in the binary oppositions as portrayed in the table 2 below.

Table 2. The binary oppositions as reflected in the story of No Witchcraft for Sale (1951)

\begin{tabular}{|l|c|c|}
\hline Main Idea & UNIVERSAL & PARTICULAR \\
\hline \multirow{4}{*}{$\begin{array}{c}\text { Supporting } \\
\text { ideas }\end{array}$} & White & Black \\
\cline { 2 - 3 } & Master & Servants \\
\cline { 2 - 3 } & Modern & Traditional \\
\cline { 2 - 3 } & Artificial & Natural \\
\cline { 2 - 3 } $\begin{array}{c}\text { Other binary } \\
\text { opposition }\end{array}$ & Foreigners & Natives \\
\cline { 2 - 3 } & & Woman \\
\cline { 2 - 3 } & Health & Sick \\
\hline
\end{tabular}

The main idea of binary logics occured in the story is particular vs universal. The particular idea goes upon Gideon who insists on keeping his tradition by not telling the White people about the herb medicine. In this part, Gideon is conflicted with the Farquars and the scientists who think of universalism that the medicine can be beneficial for others in a wide range. For the native perspective, the tradition is the wealth that should be preserved. When they give it to other people outside them, theyare being afraid ofthe destruction towards the cultural heritage and their uniqueness is missing.

Besides, from the relational process, it can be understood the polarity between master and servant. Master is represented by the Farquars. As the master, they have power over their servant. Hence, Gideon as a servant is powerless. Other polarity shows modern vs traditional, artificial vs natural, foreigner vs native. The properties of being modern, artificial, and foreigner belong to the White people. In the character of the scientists, for example, they tend to think of modern and artificial thing about the medicine. It is because town people have adapted to the modernity compared to the remote area in which the environment is still natural. Moreover, it is identified in the story they are White people, who are basically foreigners in that place. Therefore, the perspective between the native and the foreigners gets clashed.

Supporting the analysis result about binary logics, in Edward Said'sOrientalism(1978) said about postcolonial criticism in how the Western sees towards the Easterns. It is 'a specific expose of the Eurocentric universalism which takes for granted both the superiority of what is European or Western, and the inferiority of what is not'. In Orientalism, the Western considers the Easterns as 'Other'. The idea of Other is actually not only for Easterners, but also other who are not European or Westerns, including when they talk about Africans. They feel they have ability to determine, to empower, to colonize Others because Others are uneducated, immoral, and powerless. This view is reflected in the character of the Farquars and the scientist as the Whites,and Gideon and his family as Others.

\section{The Relations in the Inversion of Metaphysichierarchy}

From the binary oppositions, we see how the relation between native and the Whites is depicted. Derrida said it 'must always aim at a certain relationship, unperceived by the writer, between what he commands and what he does not command of the patterns of language that he uses... attempts to make the not-seen accessible to sight' (Derrida, 1976: 158, 163). What Derrida meant is when reading or interpret the text, it is not only 'reproducing what the writer thought or expressed in the text'. We have to find out the meaning above the meaning, which means finding something unseen in the text and sometimes make the reader 
becomes stranger with that finding. Table 2 in the previous session actually reflects the pattern of the relationship in the story. In the first reading, it can be understood that the native has no good position when he faces the Whites who charaterized as more intelligent than the natives. However, in deconstruction, such hierarchy metaphysic that has been set up by the writer can be dismantled to figure out hidden meaning.

There are three main points that become the inversion of metaphysic hierarchy regarding to the story. Firstly, Gideon sincerity to the Farquars is questionable. As a native, Gideon lives with the Farquars who are the missionary from Europe, not only himself but also his family. The Farquars have considered Gideon as a part of their family, so that they treat him well although his status is a servant. So does Gideon that considers the Farquar as his which is shown by his thought about Teddy.

... when little Teddy was born; and they were touched by the pleasureof their servants, who brought presents of fowls and eggs and flowers to the homestead when they came to rejoice over the baby, exclaiming with delight over his downy golden head and his blue eyes. (par.1)

Here we see that at the beginning it is found that there is a relation between the Whites and black as an African native. When it is related to the postcolonial study, the kindness of Gideon is not due to his true sincerity, but more about the distance between Whites and Blacks in which Whites are regarded as superior than others. Inferior feeling must be there in the native's mind, and it is reflected in the way Gideon acts towards his master who is the Farquars. There is possibility that he only wants to take the advantage(s) in living together with his master. Moreover, it is told that only few natives can live well with the Whites as the master, and Gideon is one of them. It implies that Gideon's status among natives in the society is better than other natives in common. This might be the opportunity for Gideon to be viewed as higher than other natives. Moreover, he also had a kid whose his age is similar with Teddy. It can be beneficial for Gideon that his son was also treated well and, perhaps, got adequate facility to support his life, for example in term of education, since the Farquars is the mission family who concerns the issue about human right as well. This idea about humanity is shown in the way the Farquars discussed with the scientists about the reason to take the traditional medicine.

Secondly, the Farquars and the scientists have a good purpose to create medicine from herb. We must question whether the act of the Farquars and scientists is truely a part of exploitation towards traditional heritage. There might be a good purpose of knowing the medicine so that more people can be saved from the illness, as seen in paragraph 16 written below.

.....The scientist explained how humanity might benefit if this new drug could be offered for sale;... Their feelings
over the miracle (that was how they thought of it) were so strong and deep and religious, that it was distasteful to
them to think of money. The scientist, seeing their faces, went back to his first point, which was the advancement
of humanity.... (Par. 16)

That is true that traditional medicine can be used as comodity, to take profit. However, it should be thought as well that by taking them as medical drugs, there must be reservation to keep the plants still alive or even develop them in order to be used by more people especially in Africa. It is also emphasized in paragraph 18, Mr. Farquar tried to explain to Gideon that the medicine is useful, can be put on sale in which people can get it easily, and even able to cure thousand people of African who get sick because of snake spitting. Remember the landscape of Africa is natural, and it is described as a place where the trees and plants are easy to live, mostly for tropical plants. People in Africa live among the natural landscape, while it is inevitably that sometimes they have to face the danger from the nature itself for example from wild animals or natural disaster. By finding the medicine, hopefully many people can be cured well instead of getting easy access. When the medicine is for sale, it can not be denied that money will come, but the humanity should be thought as well. So, which one is more salient? The money or humanity? And, in this case the Farquars and the scientist agree that the first thing to think is about humanity value.

Thirdly, by not telling the plant for medicine, Gideon shows his selfish towards others. The thought of the Farquars and the scientist about universality has been conflicted to the native's mind. As stated in the binary logic in the previous part, the native who is represented by Gideon tend to think in particular way. Particular in this case means the exclusiveness, by the context it is exclusiveness towards his tradition which is shown by not telling the plants for medicine. Actually it shows the Gideon the way of thinking that he is also selfish towards his own culture, that is also included as the third point of this inversion of metaphisic hierarchy. This brings us to the next question about the reason why Gideon not telling the herb medicine.

At the first part, we find that the center of the text is keeping the tradition which is very related to the the idea of universal versus particular as found in the binary opposition. It is also supported by the justification of Orientalism's theory on how the Westerns view Others. On the contrary, in decontructive reading, Derrida criticize this in different way. 'Prior to this event the existence of norm or sentre in all things was taken for granted: thus 'man', as the Renaissance sloga had it, was the measure of all things in the universe'. 'In the twentieth century, these centres were destriyed or eroded. The way the Hollocaust destroyed notion of Europe as the source and centre of human civilisation, sometimes it happened because of scientif discoveries'. By the fact given by research, the civilization is firstly begun in the East, not West, meaning that the Western is actually not that powerful and not the center of existence. 
Regarding to the Gideon's attitude toward the medicine, it means that he did not want the wealth of his natural heritage to be shared to other people. He knew that actuall the Whites did have nothing to his development, while he had potential natural resources that also beneficial for others. What was done by Gideon reflects this characteristic of over-insecurity about cultural heritage. Is this kind of thought needed and justifiable in order not help others in need? By deciding not telling the truth means that Gideon not thinking about the future. His mind is full of thoughts on how the Whites, perhaps, take them all from natives. In Gideon perpective, having the traditional medicine is enough for him. He won't shared it to public so that it can be useful for many people. It describes that he doesn't deal with any modernity offered by Farquars and scientist even though it is positive for many people. Gideon thought that he has pride when he can have the traditional heritage by himself.

\section{Disseminations Reflected in the Story}

After inverting the metaphysic hierarchy, there are new meanings in understanding the story which so called as dissemination. The first one is that keeping tradition is not always considered as right, but it might tend to bring people in egocentrism and particularism. Keeping tradition is good since it is the cultural heritage descended by the ancestors. Meanwhile, humans in this life develop from time to time, in which they are able to enhance their ability in order to create some betterment. Related to the story, the potential natural heritage is not shared by local people, who is represented by Gideon's character and the other natives. Ifcultural heritage such as traditional medicine is salient for others, the attitude of the natives for not telling the truth is not acceptable. This kind of knowledge should be shared and not to be thought as something exclusive. Their doubt about exploitation becomes unjustifiable because the medicine is important to be known, so that the more people can be cured.

For the second one, it gives the idea that people dealing with the tradition is narrow minded. Somehow, we need to change the tradition for some reasons and also when the tradition is not relevant with the today's situation. Keeping the tradition as presented in "No Witchcraft for Sale" tells that sometimes maintaining what was already done for years by our ancestors makes people ignored the changes such as modernity. They feel that changes especially if it refers to modernity is something bad and contradictory and even harm the tradition. What happened with Gideon is also happened in our society. The phenomena of onlinebasedtransportation by 2015 in Indonesia, for example, represents the conflict between traditional and modern culture. The conflict is between online-based transportation and the conventional ones in which today people in the cities prefer to use onlinebased transportation to the regular or government transportation. Wherever the online transportation, the clash happens. As mentioned in a news site kumparan.com on March 10, 2017, there is a chaos among the drivers by which conventional based drivers did not want any online-based drivers in their place because they considered the existence of application based transportation is a threat for them. The Jakarta Post also reported on November 2, 2017, that conventional taxi drivers demanded online-based transportation to be turned off. Instead of this demand, people who are the customers still support the existence of the online-based trnsportation since the modern ones give them more benefits in either time effectiveness or efficiency. This reflects on how people with conventional mind are sometimes hardly to accept the new possibilities.

Narrow-mindedness towards the tradition means that they are not open for the updates or renewals. This might bring more harm than good for the people because the tradition becomes a burdensome. We can take the example in Indonesian culture, for Batakese (Batak ethnic), to marry someone who is Batakese, the groom shoud bring "bridal price" or known as mahar in Indonesia, which is very expensive. Is it something good or not? Just imagine in the position of someone who wants to marry but he does not have any money for mahar, so should he prohibit to marry? We can also see the burial tradition in Makassar in which they should cook the buffalo meat and then shared to other in the same compund, when their member of family dies. At least five buffaloes are needed to run the ceremony, while the price of one buffalo is considerably expensive. If not, the agony cannot be buried. It happens for people when they can not hold that kind of ceremony. Consequently, the agony remains in the house and it should wait until the family members are able to have such properties.

\section{CONCLUSION}

The interpretation toward postcolonial literary work might be various. One of them can be critized by using CDA method in which it collaborates linguistic theory of Systemic Functional Grammar (SFG) and poststructuralist theory or deconstruction. It is derived that meanings are not that fixed, but we can identify the frozen ideas over the text in different way. Regarding this, we are able to recognize one of great literary works, "No Witchcraft for Sale" by Dorris Lessing, from another side under the umbrella of deconstruction analysis. At the beginning, it is found that the center of the text is about keeping the tradition done by the native represented by Gideon. He kept it from the Whites (the Farquars and the scientists) who are assumed that they want to exploit the cultural heritage. From the analysis of transitivity, the binary logics are found and generates the main polarity which is universalism (as Western repreentation) and particularism (as the natives). However, in the inverted metaphysic hierarchy, particularism that shown by not telling the truth about the traditional medicine is considered as not right. Natives who usually described as the oppressed people and good become the evil of the story. It is because they are considered as supporting egocentrism, particularism, and narrow mindedness. Simply saying, they want to be exclusive by disregarding the humanity value to help others which is portrayed by the act of telling the truth about the medicine. Meanwhile, White people who are identical with capitalism, exploitation, and colonialism, turn into a subject who is ignored and the victim of unknown culture (they do not 
know about the traditional medicine). Thus, it can be concluded that keeping tradition is not always good and the Westerns are not always bad with their ideas to make some progress as human being.

\section{References}

Barry, Peter. 2002. Beginning Theory. Manchester: Manchester University Press.

Bourdieu, P., 1982. Ce que parler veut dire: L'économie des éschanges linguistiques. Paris: Fayard.

Derrida, Jaques. 1976. 'The exorbitant question of method', pp. 157-164 in Of Grammatology, translated by GayatriChakravortySpivak. London: John Hopkins University Press.

Fadli. November 2, 2017. "Online-based driveers rally in Batam to demand return of confiscated taxi", The Jakarta Post, December 1, 2017.

Labov, William. 1981. Speech actions in personal narrative. Analyzing Discourse: Text and Talk, D. Tannen (ed.), page 217247.Washington D.C.: Georgetown University Press.

Lessing, Doris. 1951. No Withcraft for Sale. Moskow: Foreign Language Publishing House.

Lock, Graham. 1996. Functional English Grammar: An introduction for second language teachers. Melbourne: Cambridge University Press.

Loomba, Ania. 2000. Colonialism/Postcolonialism. London: Routledge.

Halliday, M.A.K. 2004. An Introduction to Functional Grammar, third edition. New York: Oxford University Press Inc.

Haryatmoko. 2016. Critical Discourse Analysis [AnalisisWacanaKritis]. Jakarta: PT RajaGrafindoPersada.

-------. 2016. MembongkarRezimKepastian: PemikiranKritis Post-strukturalis. Yogyakarta: PT Kanisius.

Norris, Christopher. 2002. Deconstruction, theory and practice, $3^{\text {rd }}$ edition. London: Routledge.

Said, Edward. 1995. Orientalism. London: Penguin Books. 